\title{
ORIENTAÇÃO DE MERCADO PARA PEQUENAS E MÉDIAS EMPRESAS DE IMIGRANTES BRASILEIROS NO EXTERIOR
}

\author{
1 Eduardo Picanço Cruz \\ 2 Roberto Pessoa de Queiroz Falcão
}

\section{Resumo}

Objetivo: contribuir para o campo de estudo do empreendedorismo, no contexto das empresas étnicas ou de imigrantes, ao analisar variáveis que definem sua orientação de mercado e as decisões estratégicas tomadas, aprofundando o conhecimento sobre o assunto.

Método: foi utilizada a coleta de dados com estratégias multimétodos (quantitativa e qualitativa), sendo sua principal estratégia a entrevista em profundidade, que compõe a análise de múltiplos casos de empreendedores no exterior, oriundos de diferentes comunidades brasileiras. Essas informações foram trianguladas, a partir de dados de surveys realizadas com brasileiros na Austrália, no Canadá, em Portugal e na Estônia, da netnografia e da análise documental. Sendo assim, análises intra e intercasos foram feitas, visando encontrar similaridades e diferenças nos resultados alcançados.

Originalidade/Relevância: o artigo enfoca uma importante questão, que envolve as grandes economias mundiais - os imigrantes. Dadas as dificuldades em sua inserção nas sociedades acolhedoras, eles tendem a ser identificados como "problemas sociais". Por outro lado, a aplicação de modelos de negócios e de propostas de orientação mercadológica para empreendedores imigrantes, viabiliza um caminho para a sua ascensão econômica e social. Ao se tornarem empreendedores bem-sucedidos, eles podem reverter essa percepção discriminatória a seu respeito.

Resultados: com base nos dados coletados, bem como na análise de artigos da literatura existente, foram identificadas quatro orientações diferentes de mercado: (1) foco no nicho de mercado étnico, (2) foco em interesses específicos, (3) foco em produtos exóticos para o cliente local, e (4) foco em mercados altamente competitivos. Uma matriz 2 × 2 é apresentada, incluindo as variáveis: (a) grau de afiliação de empreendedores com suas comunidades étnicas e seu público-alvo, e (b) segmentos de mercado enfocados.

Contribuições teóricas/metodológicas: uma das principais contribuições teóricas deste artigo é apoiar a discussão sobre a orientação para o mercado de imigrantes, os empreendimentos étnicos e as decisões do público-alvo a ser atendido. Além disso, o artigo inova, ao discutir decisões estratégicas, no contexto de pequenos e médios negócios de brasileiros no exterior.

Palavras-chave: Empreendedor imigrante. Orientação de mercado. Oportunidade de mercado. Enclave étnico. Imigração.

Recebido: 31/10/2019 / Aprovado: 24/03/2020

Editor responsável: Profa. Dra. Vânia Maria Nassif

Processo de avaliação: Double Blind Review

Doi: https://doi.org/10.14211/regepe.v9i4.1765

1 Universidade Federal Fluminense - UFF, Rio de Janeiro, (Brasil). E-mail: epicanco@id.uff.br

2 Universidade Federal Fluminense - UFF, Rio de Janeiro, (Brasil). E-mail: robertopqfalcao@gmail.com Orcid id: https://orcid.org/0000-0001-9544-1973 


\title{
MARKET ORIENTATION FOR IMMIGRANT AND ETHNIC SMALL AND MEDIUM- SIZED BRAZILIAN IMMIGRANT VENTURES OVERSEAS
}

\begin{abstract}
Objective: contribute to the entrepreneurship field of study, in the context of ethnic or immigrant companies, by analyzing variables that define their market orientation and the strategic decisions taken, deepening the knowledge on the subject.

Method: the data collection was comprised of multi-method strategies (quantitative and qualitative), the main strategy being an in-depth interview, which comprises the analysis of multiple cases of overseas entrepreneurs, from different Brazilian communities. This information was triangulated, based on data from surveys carried out with Brazilians in Australia, Canada, Portugal and Estonia, from netnography and document analysis. Therefore, intra and inter-case analyzes were carried out, aiming to find similarities and differences in the results achieved.
\end{abstract}

Originality/Relevance: the article focuses on an important issue, which involves the world's major economies - immigrants. Given the difficulties in their insertion in host societies, they tend to be identified as "social problems". On the other hand, the application of business models and proposals for immigrant entrepreneurs' market orientation enables a path for their economic and social ascension. By becoming successful entrepreneurs, they can reverse this discriminatory perception of themselves.

Results: based on the data collected as well as the analysis of articles from the existing literature, four different market orientations were identified: (1) focus on ethnic market niche, (2) focus on specific interests, (3) focus on exotic products for the local customer, and (4) focus on highly competitive markets. The authors present a 2x2 matrix including the variables: (a) degree of affiliation of entrepreneurs with their ethnic communities and target audience, e (b) market segments in which they focus.

Theoretical/Methodological contributions: the main theoretical contribution of the paper is supporting the discussion on market orientation of immigrants and ethnic firms, as well as their target audience decisions. In addition, the article innovates by discussing strategic decisions in the context of small and medium Brazilians businesses established overseas.

Keywords: Immigrant entrepreneur. Market orientation. Market opportunity. Ethnic enclave. Immigration. 


\section{ORIENTACIÓN DE MERCADO PARA PEQUEÑAS Y MEDIANAS EMPRESAS DE INMIGRANTES BRASILEÑOS EN EL EXTRANJERO}

\section{Resumen}

Objetivo: contribuir al campo de estudio del emprendimiento, en el contexto de empresas étnicas o inmigrantes, mediante el análisis de variables que definen su orientación al mercado y las decisiones estratégicas tomadas, profundizando el conocimiento sobre el tema.

Método: se utilizó la recolección de datos con estrategias multimétodos (cuantitativas y cualitativas), siendo la principal estrategia la entrevista en profundidad, que comprende el análisis de múltiples casos de emprendedores en el exterior, de diferentes comunidades brasileñas. Esta información fue triangulada, a partir de datos de encuestas realizadas con brasileños en Australia, Canadá, Portugal y Estonia, de netnografía y análisis documental. Así, se realizaron análisis intra e inter-casos, con el objetivo de encontrar similitudes y diferencias en los resultados obtenidos.

Originalidad / Relevancia: el artículo se centra en un tema importante que involucra a las principales economías del mundo: los inmigrantes. Dadas las dificultades para su inserción en sociedades de acogida, suelen identificarse como "problemas sociales". Por otro lado, la aplicación de modelos de negocio y propuestas de orientación al mercado para emprendedores inmigrantes, abre un camino para su ascenso económico y social. Al convertirse en empresarios exitosos, ellos pueden revertir esta percepción discriminatoria de sí mismos.

Resultados: en base a los datos recolectados, así como al análisis de artículos en la literatura existente, se identificaron cuatro orientaciones de mercado diferentes: (1) enfoque en el nicho de mercado étnico, (2) enfoque en intereses específicos, (3) enfoque en productos exótico para el cliente local, y (4) enfoque en mercados altamente competitivos. Se presenta una matriz de 2 × 2, que incluye las variables: (a) grado de afiliación de los emprendedores con sus comunidades étnicas y su público objetivo, y (b) segmentos de mercado focalizados.

Aportes teórico-metodológicos: uno de los principales aportes teóricos de este artículo es apoyar la discusión sobre la orientación hacia el mercado inmigrante, las empresas étnicas y las decisiones del público objetivo a atender. Además, el artículo innova, al discutir decisiones estratégicas, en el contexto de las pequeñas y medianas empresas de brasileños en el exterior.

Palabras clave: Emprendedor inmigrante. Orientación del mercado. Oportunidad de mercado. Enclave étnico. Inmigración. 


\section{INTRODUÇÃO}

Praticamente todas as nações das sociedades capitalistas abrigam "minorias desfavorecidas" (Jones, Barrett, \& McEvoy, 2000), representadas, em parte, por grupos étnicos ou de imigrantes, que criam milhares de empresas em vários países. Segundo o relatório das Nações Unidas (United Nations, 2017), o número de migrantes internacionais, em todo o mundo, foi de 258 milhões, em 2017. Destes, 78 milhões vivem na Europa, e 58 milhões, na América do Norte, sendo 50 milhões, apenas nos EUA.

Apesar das dificuldades, muitos desses imigrantes tornam-se empreendedores no exterior. Nesse sentido, Vandor e Franke (2016) destacam que as experiências interculturais aumentam a capacidade desses indivíduos para a identificação de ideias de negócios promissoras. Assim, eles encontram novos produtos e serviços, identificam preferências dos clientes, e desenvolvem estratégias de comunicação, criando soluções inovadoras em seus países de destino.

A realidade, para a maioria desses empreendedores, está nas especificidades de comunidades étnicas e co-étnicas - os chamados "enclaves étnicos" (Drori, Honig, \& Wright, 2009), responsáveis por determinar sua orientação para o mercado, suas decisões estratégicas, bem como a sobrevivência e a segmentação de suas firmas, voltadas, muitas vezes, a um empreendedorismo por necessidade (Rath \& Kloosterman, 2000).

Obras seminais começaram a discutir a relação entre a etnia e o empreendedorismo (Aldrich \& Waldinger, 1990), concentrando-se em características de empreendedores individuais, identificadas como autoemprego ou empresas iniciantes (Rath \& Kloosterman, 2000).

Tanto Altinay (2009) quanto Wang e Altinay (2012) objetivaram discutir a orientação empreendedora, em pequenas empresas étnicas, revelando que elas operam em um forte ambiente sociocultural, que influencia sua orientação para o mercado. Altinay (2009), por exemplo, mostrou que, ao permanecer em suas comunidades étnicas, essas empresas não são capazes de atrair clientes locais, situados fora das barreiras do enclave étnico, e, por isso, exibem dificuldades para responder às mudanças nas condições do mercado. Assim, sua orientação para o mercado resulta da interação entre as mudanças nos ambientes de negócios étnicos e aquelas que ocorrem nos tradicionais (Altinay \& Altinay, 2008).

Embora a literatura existente tenha explorado muitos aspectos de pequenas empresas étnicas ou de imigrantes, eles estão ligados ao entendimento social e cultural 
dos negócios (Saxenian, 2007; Aliaga-Isla \& Rialp, 2013; Elo \& Volovelsky, 2016). Há, então, uma lacuna teórica remanescente, pois falta aprofundar o conhecimento, por meio de uma matriz de análise conceitual, para identificar possíveis orientações de mercado a esses empreendedores (ver Elo, 2016; Elo et al., 2018).

Este trabalho, por conseguinte, preenche essa lacuna e amplia esse conhecimento, fazendo a interseção entre os estudos dos empreendedorismos da diáspora e étnico, para evidenciar as variáveis que influenciam as estratégias de mercado das empresas étnicas ou constituídas por imigrantes. Para tanto, foram considerados os esforços iniciais: (1) do trabalho sociológico, como o de Zhou (2004), que delineou uma categorização das oportunidades de mercado do nicho étnico; e (2) da área negócios internacionais, como os estudos de Wang e Altinay (2012), que analisaram casos específicos de empresas étnicas.

$\mathrm{Na}$ configuração dessa matriz, os autores exploram aspectos de empreendedores imigrantes, que não experimentaram, necessariamente, trajetórias diaspóricas, mas que imigraram isoladamente. Ademais, esta pesquisa traz uma contribuição para o campo dos estudos de empreendedorismo étnico ou imigrante, introduzindo conceitos de gestão nas discussões relacionadas às oportunidades de negócios e de marketing. A matriz traça, portanto, possíveis relações entre: (a) o nível de afiliação dos empreendedores (Schimmele \& Wu, 2015) às suas comunidades étnicas; e (b) suas escolhas de públicosalvo - clientes étnicos ou clientes locais (Bonacich, 1973).

Sendo assim, as principais questões de pesquisa, que nortearam este estudo, são:

[PP1] Os empreendedores imigrantes ou étnicos são influenciados por sua afiliação às comunidades étnicas, ao escolherem sua orientação de mercado, ou ao tomarem suas decisões estratégicas?

[PP2] A definição do público-alvo das empresas (étnicos, co-étnicos, consumidores e clientes locais) leva a quais diferentes orientações mercadológicas?

Para atingir os objetivos deste estudo, foi realizada uma robusta coleta de dados qualitativos, complementada por outras estratégias. Mais de seis anos de trabalho de campo, incluindo entrevistas em profundidade e observação de pequenos empreendedores imigrantes, auxiliaram os autores a desenhar uma matriz, que visa endereçar lacunas conceituais nas teorias de empreendedorismo imigrante, especialmente as ligadas às economias de enclave e às decisões de mercado (Zhou, 2004), ancoradas em trabalhos oriundos do campo da sociologia. 
Os empreendedores brasileiros foram escolhidos como foco da coleta de dados, embora a matriz tenha sido também fundamentada por uma revisão sistemática da literatura acerca do empreendedorismo étnico ou imigrante, conduzidos no seio de comunidades étnicas das mais variadas - reforçando a ideia de se refinar a teoria do empreendedorismo étnico, por meio de estudos comparativos com outras comunidades de imigrantes (Jones \& Ram, 2010).

\section{REFERENCIAL TEÓRICO}

Esta seção está dividida em duas abordagens principais: (1) uma revisão da literatura, incluindo tanto autores seminais quanto os mais recentes, que aborda o tema dos enclaves étnicos e a sua influência nas decisões das empresas de imigrantes, explorando a interseção entre as decisões das empresas étnicas e suas orientações de mercado; e (2) questões acerca da orientação de mercado de empresas étnicas, analisadas e comparadas com a literatura existente, sobre o empreendedorismo internacional, a diáspora, e o empreendedorismo imigrante ou étnico.

Lentes múltiplas e interdisciplinares podem ser empregadas no entendimento do fenômeno do empreendedorismo imigrante ou étnico, que, naturalmente, ocorre em várias camadas (Coviello \& Yli-Renko, 2016; Etemad, 2017). Isso se explica pelo fato de o fenômeno envolver temas tão diversos, quanto geografia e política, migração internacional, recursos humanos internacionais, sociologia e capital humano.

Segundo Etemad (2018), trabalhos recentes sobre o empreendedorismo étnico ou imigrante fizeram um esforço para conectar alguns conceitos, inerentemente difíceis, ao empreendedorismo internacional (IE), devido à sua formação internacional e experiências anteriores (Elo, 2016; Elo et al., 2018). Consequentemente, os empreendedores migrantes e da diáspora trazem seu conhecimento, decorrente de sua cultura e vivência nos mercados domésticos de origem, o que reflete uma expertise de negócios, passível de adequação, para operar em contextos internacionais (Etemad, 2017) e transnacionais (Drori, Honig, \& Wright, 2009).

Riddle e Brinkerhoff (2011) destacam três lacunas nas disciplinas de gestão e de marketing, que, há muito, concentram-se em aspectos de como a aculturação dos migrantes afeta seu comportamento nos países anfitriões: (1) a maneira como a exploração de oportunidades ocorre; (2) a influência do capital social e das redes nas decisões das empresas; e (3) a influência do meio ambiente na determinação de estratégias ou foco no mercado. 
O estudo de imigrantes ou empreendedores étnicos evoluiu, inserido em duas principais vertentes da literatura acadêmica: (1) o empreendedorismo internacional, que estuda o fenômeno de mercado da globalização, e seus efeitos nos mercados transnacionais (por exemplo, Drori, Honig e Wright, 2009; Dimitratos, Plakoyiannaki, Pitsoulaki e Tüselmann, 2010); e (2) os fatores do microambiente, que interferem nas empresas étnicas, discutindo as dificuldades de adaptação e a configuração de redes nos enclaves étnicos (por exemplo, Portes \& Zhou, 1992; Achidi-Ndofor \& Prime, 2011) - que serão melhor explicadas nas seções subsequentes.

\subsection{OS ENCLAVES ÉTNICOS E SUA INFLUÊNCIA NAS DECISÕES DAS EMPRESAS DE IMIGRANTES}

Os enclaves étnicos, ao mesmo tempo que podem reduzir as barreiras a novos imigrantes, também aumentam as oportunidades econômicas, formando redes de segurança, que alavancam recursos para o estabelecimento de firmas de imigrantes (Drori, Honig, \& Wright, 2009). Embora o ambiente cultural da comunidade envolva essas empresas, os aspectos econômicos, políticos e socioculturais do país de acolhimento também as afetam (Barrett, Jones, \& McEvoy, 1996), pois se beneficiam da disponibilidade de trabalhadores étnicos, muitas vezes informais, que aceitam receber salários mais baixos (Portes \& Zhou, 1992).

Além disso, os enclaves étnicos constituem um canal para disseminar práticas comerciais e acessar informações, em mercados-chave ou relacionadas a fornecedores específicos e confiáveis. Ademais, as comunidades étnicas podem promover acesso a crédito informal, adicionalmente aos mecanismos formais, exceto para aqueles que estão experimentando uma situação de migração ilegal (Light, Bhachu, \& Karageorgis, 1993).

Nesse sentido, Portes e Zhou (1992) argumentam que o empreendedorismo étnico promove uma forma alternativa de mobilidade econômica, mostrando como os recémchegados apresentam uma rápida ascensão econômica, com lucros remetidos aos países de origem. Outra descoberta crucial da pesquisa desses autores foi a "confiança limitada" (bounded trust), ou a solidariedade entre os participantes dos enclaves, considerados entidades culturalmente integradas, capazes de promover laços de solidariedade e de confiança entre os participantes. Os indivíduos locais, muitas vezes, tratam os imigrantes de forma diferente, o que pode gerar uma conscientização maior de seus símbolos nacionais comuns, e um sentimento de apoio mútuo, construindo uma espécie de "rede de proteção", envolvendo o consumo de itens associados ao seu país de origem e a valorização do trabalho entre si. 
Mais recentemente, Tata e Prasad (2015) apresentaram um entendimento avançado de como o capital social geral dos proprietários de empresas familiares influencia o desempenho dos negócios. Além disso, Tolciu (2011) estabelece que o fenômeno do empreendedorismo migrante só pode ser compreendido a partir da contabilização das variáveis externas e das limitações internas da empresa. O autor evidencia uma abordagem de racionalidade limitada, pela qual os resultados empresariais podem ser vistos como uma questão de otimização sob restrições. Ademais, de acordo com Riddle e Brinkerhoff (2011), nos países de assentamento, as diásporas enfrentam ambientes institucionais, em geral, significativamente diferentes dos de seus países de origem, causando a exposição e a adoção de papéis e de relações institucionais associados a uma nova cultura.

Cruz, Falcão e Barreto (2017) demonstraram que, em algumas comunidades brasileiras no exterior, as relações de apoio mútuo, identificadas por Portes e Zhou (1992), eram incipientes ou não existiam. Em muitos casos, foi evidenciado, inclusive, um sentimento de desconfiança, e até mesmo repulsa ou vergonha, ao frequentarem ambientes tipicamente de cultura brasileira. Um baixo grau de associação entre os empreendedores, reforçado pelas dificuldades de se organizarem em rede, foram evidenciados por esses autores, que pesquisaram as comunidades brasileiras no estrangeiro.

A importância do capital social de imigrantes é mostrada também em outros contextos europeus e norte-americanos, por autores, como: Forsander (2004), Cheong, Edwards, Goulbourne e Solomos (2007), e Herreros e Criado (2009). Nesse sentido, operando de maneira isolada, os empresários perdem a força das relações políticas, econômicas e sociais, se comparados às associações de outras etnias. Assim, o empreendedorismo brasileiro, de pequeno porte, bem-sucedido no exterior, parece derivar de iniciativas de indivíduos enérgicos e automotivados, detentores de um alto grau de confiança pessoal, e/ou propensos ao risco inerente do empreendimento em terras além-mar (Cruz, Falcão, \& Barreto, 2017).

Destaca-se, ainda, acerca do capital social, que a literatura existente sobre o empreendedorismo imigrante está concentrada em condições específicas, decorrentes da exploração de redes de apoio aos imigrantes (ver: Luken \& Tranmer, 2010; Hurtado-deMendoza, Gonzales, Serrano, \& Kaltman, 2014), explicitadas a seguir. Além disso, ela sugere que esses tipos de empresas não se limitam a promover o trabalho autônomo (autoemprego) e o estabelecimento no país anfitrião, mas são orientadas por fontes de 
vantagem competitiva, dadas as capacidades de seus empreendedores (Zolin \& Schlosser, 2013), que podem abranger tanto suas internas quanto suas relações sociais.

Ainda segundo Safran (1991), outra definição importante é a do fenômeno da diáspora, que abrange imigrantes e seus descendentes, os quais mantêm uma relação estreita com seus países de origem. Assim, os membros das diásporas são imigrantes que se estabelecem em um só lugar, que se reagrupam, estando em um estado contínuo de formação (Cohen, 2008). Em contrapartida, Riddle, Hrivnak e Nielsen (2010) definem empresários da diáspora transnacional como migrantes e seus descendentes, que estabelecem atividades empreendedoras, abrangendo os ambientes empresariais nacionais de seus países de origem e de residência.

Vários estudiosos, como Portes e Zhou (1992), Barrett, Jones e McEvoy (1996), Rath e Kloosterman (2000), bem como Cruz, Falcão e Barreto (2017), pesquisaram as características gerais do empreendedorismo étnico, incluindo seu ambiente social, para enfatizar os aspectos sociológicos do fenômeno (Aliaga-Isla \& Rialp, 2013), haja vista o impacto das redes de apoio aos imigrantes, durante o início dos negócios (Saxenian, 2007), ou o empreendedorismo social (Elo \& Volovelsky, 2016). Portanto, as redes sociais são baseadas em conexões com os consumidores, e alianças interorganizacionais, que influenciam a cocriação de oportunidades, por meio da articulação de disputas comerciais (Brinkerhoff, 2016). Outro aspecto crucial das redes sociais de imigrantes é o seu grau de assimilação (Alba \& Nee, 1997). Segundo Achidi-Ndofor e Priem (2011), os empreendedores imigrantes, socialmente identificados com suas comunidades étnicas, são mais propensos a se tornarem empreendedores de enclaves étnicos, enquanto estiverem ligados às suas comunidades por tradição, prestígio ou mesmo por mero destino. Portanto, não é incomum que eles se envolvam em atividades para melhorar o status das suas comunidades, como o levantamento de fundos, para construir instalações comunitárias; o auxílio a um futuro concorrente, em seu estabelecimento, no país ou no enclave (Lee, 1999); ou o uso de relacionamentos para obter acesso a recursos-chave, como fornecedores e trabalhadores (Portes \& Zhou, 1992).

Por outro lado, há empreendedores que dificilmente se identificam com seus grupos étnicos (Ellemers, Van Rijswijk, Roefs, \& Simons, 1997), ou, eventualmente, desprezamnos (Spears, Doosje, \& Ellemers, 1997). Segundo Rusinovic (2008), os empreendedores étnicos de segunda geração são mais ativos nos mercados locais, mudando de um mercado para outro, pelo uso estratégico de sua etnia.

Em um trabalho mais recente, Tata e Prasad (2015) apresentaram um entendimento avançado de como o capital social dos empreendedores familiares influencia 0 
desempenho de seus negócios. Além disso, Tolciu (2011) postula que a compreensão do fenômeno do empreendedorismo migrante deve considerar tanto as variáveis externas quanto as limitações internas da empresa.

\subsection{ORIENTAÇÃO DE MERCADO DE EMPRESAS ÉTNICAS}

A orientação para o mercado e o desempenho dos negócios está fortemente associada (Kara, Spillan, \& DeShields, 2005; Kirca, Jayachandran, \& Bearden, 2005; Matsuno, Mentzer, \& Rentz, 2005; Slater \& Narver, 1994). De acordo com Agarwal, Erramilli e Dev (2003), quando uma empresa é orientada para o mercado, ela tende a ser melhor coordenada internamente, tornando-se também superior quanto às suas capacidades de vinculação de clientes e de detecção de mercado.

As empresas étnicas, que visam atender a seus compatriotas, todavia, podem usar uma abordagem effectual (Sarasvathy, 2001) para os negócios, uma vez que a orientação para o mercado pode surgir naturalmente, por causa da cultura dos empreendedores (Slater \& Narver, 1994).

Como apontado por Altinay (2009), a orientação para o mercado é composta por três elementos-chave: (1) a orientação do cliente - engloba uma atitude contínua e proativa em relação às exigências e feedbacks dos clientes; (2) a orientação do concorrente - abrange a compreensão tanto das forças e das fraquezas competitivas de curto prazo, como das capacidades e estratégias de longo prazo, dos concorrentes (atuais e potenciais); e (3) a coordenação interfuncional - abarca a aprendizagem organizacional, relativa ao compartilhamento de informações entre departamentos, ao desenvolvimento e à implementação de estratégias de negócios (Deng \& Dart, 1994; Slater \& Narver, 1994).

Zhou (2004) também aborda as estruturas de oportunidade para empreendedores imigrantes, identificando três focos para esses empreendedores: (1) nichos de mercado étnico; (2) oportunidades no mercado convencional; e (3) venda de produtos exóticos para os clientes locais.

Embora a administração desempenhe um papel significativo na formação da orientação para o mercado de pequenas empresas (Jaworski \& Kohli, 1993), não é diferente em negócios étnicos. Atitudes, mentalidade e antecedentes culturais de risco podem influenciar sua orientação para o mercado. Além disso, quanto maior for a instabilidade no mercado e quanto maior a intensidade da concorrência, mais forte será o vínculo entre a orientação para o mercado e o desempenho dos negócios.

Pequenas empresas étnicas têm maior flexibilidade e proximidade com seus clientes e mercados. Isso resulta em decisões rápidas e implementação de estratégias (McCartan- 
Quinn \& Carson, 2003). Portanto, relacionamentos mais próximos com seus clientes étnicos criam vantagem competitiva (Tzokas, Carter, \& Kyriazopoulos, 2001).

Além disso, a pequena empresa é geralmente simplista, orientada internamente, usando uma abordagem effectual para o planejamento de negócios (Sarasvathy, 2001), que segue a lógica de utilizar os recursos disponíveis no momento, ao invés de se prender a um plano de negócios. De acordo com Pelham (2000), essa forma effectual de empreender funciona em uma visão de curto prazo.

As empresas étnicas, contudo, devem considerar a influência da etnia em ambos os lados da oferta do produto e do serviço: consumidores e fornecedores. Sua afiliação e valores étnicos relacionam-se a características comumente compartilhadas, envolvendo um senso de costumes comuns, comida, linguagem, vestuário, religião e normas (Jamal, 2003), capazes de afetar transações comerciais entre empresas étnicas e co-étnicas, bem como as relações com clientes tradicionais.

Há, também, o fato de que as empresas étnicas constituem uma plataforma para o intercâmbio cultural entre os empreendedores étnicos e seus clientes tradicionais. Elas desenvolvem, por exemplo, estratégias para identificar nichos de mercado e facilitar o consumo de produtos étnicos entre os clientes locais, oferecendo-os a preços competitivos, para "educar" e informar os clientes locais (Altinay, 2009).

Para concluir, Altinay (2009) postula, igualmente, que a estrutura centralizada das empresas étnicas, gerenciadas e administradas pelos proprietários, tem implicações para diferentes dimensões de orientação para o mercado. Isso se dá porque tais empresas se beneficiam de um contato próximo e informal com seus clientes, por meio do envolvimento de seus proprietários (ou membros da família) com as transações comerciais.

Sendo assim, empresas que, outrora, restringiam-se ao nicho de mercado étnico, e competiam apenas com seus pares co-étnicos pela sobrevivência; atualmente, veem o varejo tradicional vender produtos étnicos, e atrair continuamente "imigrantes de segunda geração", cujas necessidades e desejos estão mais alinhados com os do seu país anfitrião (Altinay \& Altinay, 2006). Esse cenário, então, exerce maior pressão sobre as empresas étnicas, levando-as a ampliar sua abrangência, a fim da sua manutenção no mercado.

Por outro lado, o foco no nicho étnico apresenta certas vantagens competitivas, relacionadas à estratégia de desenvolvimento de mercado, proposta por Ansoff (1957), em sua matriz. Seu modelo de negócios captura valor por intermédio de um enfoque étnico de produtos e de serviços valorizados, que caracterizam uma escolha estratégica específica (Moussetis, 2011; Novo \& Padilha, 2017). 
De acordo com Nkongolo-Bakenda e Chrysostome (2013), para os membros da diáspora, que se envolvem em atividades empresariais, a identificação de oportunidades de negócios é tanto um passo crucial como um fator crítico para alcançar o sucesso. Além disso, para esses autores, oportunidades empreendedoras remetem a uma situação, em que novos bens ou serviços podem ser introduzidos e vendidos a um preço mais alto do que seu custo de produção.

\section{PROCEDIMENTOS METODOLÓGICOS}

\subsection{COLETA DE DADOS}

Os empreendedores brasileiros foram escolhidos como foco do estudo, porque o crescente fenômeno do estabelecimento de seus negócios no exterior continua sendo insuficientemente estudado.

Todas as entrevistas foram realizadas na língua nativa dos empreendedores participantes (português), o que ajudou a desenvolver relacionamentos pessoais com eles, facilitando o entendimento do senso de comunidade étnica. Além disso, o fato de os pesquisadores também serem brasileiros permitiu que os informantes de minorias étnicas fossem acessados (Blackburn \& Kovalainen, 2009).

A coleta de dados abrangeu um longo período de seis anos, que possibilitou à equipe de pesquisa estabelecer conexões mais profundas com empreendedores imigrantes brasileiros, ajudando a entender melhor certos padrões, comportamentos e significados inerentes à cultura.

Dado que o objetivo da pesquisa era o de preencher a lacuna teórica, pela proposição de uma matriz conceitual, passível de posterior replicação, em maior escala, e pela identificação de possíveis orientações de mercado para empreendedores étnicos ou imigrantes (Elo, 2016; Elo et al., 2018), foram realizadas diversas estratégias de coleta de dados, a fim de avaliar os múltiplos casos, conforme está explicitado a seguir.

Durante quatro anos, foram realizadas 90 entrevistas em profundidade, baseadas no método de entrevista de McCracken (1988), com empreendedores oriundos de três comunidades de imigrantes brasileiros, em(na): Flórida (Orlando, Pompano Beach e Doral). A escolha por essas comunidades se deu por sua condição de segunda maior concentração geográfica étnica brasileira (Bloem, 2015) nos EUA, atrás apenas da região de Boston.

Ao longo do caminho, para se aproximarem do universo dos imigrantes, os pesquisadores obtiveram insights e perspectivas, difíceis de alcançar por meio de um envolvimento menos sustentado. Por isso, houve a necessidade de criar um roteiro para 
as entrevistas em profundidade (Figura 1), que seguiu o protocolo de Marschan-Piekkari e Welch (2011), e se inspirou, igualmente, nas pesquisas de Zhou (2004) e de Rocha, Esteves, Mello e Silva (2015).

\begin{tabular}{l|l}
\hline Tópicos & Itens do roteiro semiestruturado das entrevistas \\
\hline $\begin{array}{l}\text { Informações sobre o empreendedor, } \\
\text { quando ainda morava no Brasil. }\end{array}$ & $\begin{array}{l}\text { Perfil do indivíduo e de sua família, atividades econômicas } \\
\text { desenvolvidas etc. }\end{array}$ \\
\hline $\begin{array}{l}\text { Informações sobre a saída do Brasil. } \\
\text { Informações sobre a abertura da } \\
\text { empresa no exterior. }\end{array}$ & $\begin{array}{l}\text { Ootivão para deixar o Brasil, tempo do processo, modo de } \\
\text { entrada no país estrangeiro, se a família foi junto etc. }\end{array}$ \\
\hline $\begin{array}{l}\text { Informações atualizadas sobre a a difades enfrentadas etc. } \\
\text { empresa. }\end{array}$ & Clientes, redes de apoio, modelo de gestão etc. \\
\hline Perspectivas de futuro. & $\begin{array}{l}\text { Intenções de retornar ao Brasil, fazer negócios com o Brasil } \\
\text { (transnacionalismo). }\end{array}$ \\
\hline
\end{tabular}

Figura 1. Roteiro das entrevistas

Fonte: Elaborada pelo autor.

A triangulação com as partes interessadas da comunidade (advogados, líderes comunitários e contadores), por meio de entrevistas e reuniões, visou a compreensão dos aspectos legais das empresas imigrantes constituídas e de sua percepção.

As estratégias qualitativas de coleta de dados, ora relatadas, possibilitaram à equipe de pesquisa contatos mais profundos com os empreendedores imigrantes, sendo, ainda, complementadas pelas estratégias e fontes de pesquisa, a seguir indicadas:

(1) contatos, via Skype e e-mail, com dez imigrantes brasileiros-japoneses (decasséguis), que residem no Japão, e com um empresário judaico-brasileiro, que empreendeu em Israel;

(2) entrevistas em profundidade com outros 15 empresários brasileiros, na Austrália, e oito, na Estônia;

(3) análise documental de sites e fanpages, e a realização de netnografia (segundo os protocolos de pesquisa de Kozinets, 2002), em diversas comunidades virtuais de brasileiros, no Facebook: "Brasileiros em Sydney", "Brasileiros em Perth" etc. (Austrália); "Brasileiros em Ibiza", entre outros (Espanha); "Brasileiros na Dinamarca", entre outros (Dinamarca); "Brasileiros em Aveiro, "Apoio brasileiros em Lisboa", entre outros (Portugal); "Brasileiros em Toronto", entre outros (Canadá); "Brasileiros na Estônia", entre outros (Estônia) e "Network Nacional de Brasileiros no Japão (NNBJ)", "Brasileiros no Japão" entre outros (Japão);

(4) confronto com a literatura existente sobre as comunidades étnicas brasileiras (Bloem, 2015; Teixeira \& Souza, 2014; Teixeira, 2014; Rocha, Esteves, Mello, \& Silva, 2015), e outros grupos étnicos, tais como: chineses, mexicanos, dominicanos 
Orientação de Mercado para Pequenas e Médias Empresas de Imigrantes Brasileiros no Exterior

(Portes \& Zhou, 1992), portugueses (Teixeira, 2001) e turcos (Wang \& Altinay, 2012);

(5) surveys com brasileiros na Austrália $(N=610)$, Canadá $(N=676)$, Portugal $(N=$ 625) e Estônia ( $N=50$ ), para identificar o perfil dos imigrantes brasileiros nesses países, bem como suas motivações para emigrar e se estabelecer nos países de acolhimento. O roteiro das surveys (Figura 2) foi inspirado no trabalho acerca dos brasileiros, em Londres, de Evans et al. (2007).

\begin{tabular}{l|l}
\hline Tópicos & Itens da survey \\
\hline $\begin{array}{l}\text { Informações sobre o indivíduo, } \\
\text { enquanto ele ainda morava no } \\
\text { Brasil. }\end{array}$ & Perfil socioeconômico do indivíduo e de sua família, formação etc. \\
\hline $\begin{array}{l}\text { Informações sobre a sua saída } \\
\text { do Brasil. }\end{array}$ & $\begin{array}{l}\text { Motivação para deixar o Brasil; modo de entrada no país estrangeiro; por } \\
\text { que o país atraiu o respondente; qual o propósito; quais as dificuldades } \\
\text { iniciais etc. }\end{array}$ \\
\hline $\begin{array}{l}\text { Informações atualizadas sobre } \\
\text { o respondente. }\end{array}$ & $\begin{array}{l}\text { Com quem mora, quais as dificuldades atuais, como está se sustentando } \\
\text { etc. }\end{array}$ \\
\hline Perspectivas de futuro. & $\begin{array}{l}\text { Intenções de retornar ao Brasil; se pretende empreender no país que está } \\
\text { morando. }\end{array}$ \\
\hline
\end{tabular}

Figura 2. Descrição da Survey

Fonte: Elaborada pelo autor.

Um pequeno exemplo dos dados colhidos pelas surveys é apresentado a seguir (Tabela 1).

Tabela 1

Informações básicas colhidas na survey

\begin{tabular}{l|l|l|l|l}
\hline Sexo & Austrália & Canadá & Portugal & Estônia \\
\hline Masculino & $39,50 \%$ & $39,40 \%$ & $37,90 \%$ & $63,2 \%$ \\
\hline Feminino & $60,50 \%$ & $60,60 \%$ & $62,10 \%$ & $36,8 \%$ \\
\hline \multicolumn{5}{|l}{} \\
\hline Idade & Austrália & Canadá & Portugal & Estônia \\
\hline Até 20 & $4,8 \%$ & $0,6 \%$ & $3,2 \%$ & $1,8 \%$ \\
\hline 21 a 30 & $56,9 \%$ & $33,0 \%$ & $34,5 \%$ & $35,1 \%$ \\
\hline 31 a 40 & $30,4 \%$ & $46,6 \%$ & $32,1 \%$ & $50,9 \%$ \\
\hline 41 a 50 & $5,8 \%$ & $17,3 \%$ & $20,0 \%$ & $7,0 \%$ \\
\hline mais de 51 & $2,1 \%$ & $2,5 \%$ & $10,2 \%$ & $5,3 \%$ \\
\hline \multicolumn{5}{|l|}{} \\
\hline Escolaridade & Austrália & Canadá & Portugal & Estônia \\
\hline Ensino Fundamental & $0,5 \%$ & $0,9 \%$ & $1,8 \%$ & $17,5 \%$ \\
\hline Ensino Médio & $16,9 \%$ & $6,3 \%$ & $20,8 \%$ & $3,5 \%$ \\
\hline Graduação & $51,3 \%$ & $44,9 \%$ & $41,3 \%$ & $49,1 \%$ \\
\hline Pós-Graduação & $31,3 \%$ & $47,9 \%$ & $36,1 \%$ & $29,8 \%$ \\
\hline
\end{tabular}

Fonte: Elaborada pelos autores, a partir de dados das surveys. 
Vale explicar que: (a) as diferentes metodologias e técnicas de coleta de dados, incluídas pelos pesquisadores, foram combinadas, de maneira sistemática e crescente (Stake, 2013; Marschan-Piekkari \& Welch, 2011); (b) o Skype e as videoconferências serviram de alternativas às limitações orçamentárias para a realização de viagens a países mais distantes; e (c) a análise documental e o confronto com a literatura sobre o tema, permitiram aos autores desenvolver suas próprias contribuições para a teoria (Denzin \& Lincoln, 2011).

Quanto à abordagem abdutiva (Dubois \& Gadde, 2002), adotada pela equipe de pesquisa, ela se caracterizou por um processo iterativo dos dados empíricos com a observação de campo. Assim, a pesquisa evoluiu gradualmente, à medida que o trabalho de campo e a teoria latente interagiam contínua e ciclicamente, permitindo que fatos relevantes ocorressem nesse processo interativo. Nesse sentido, no decorrer do período de imersão, os pontos de vista mudaram, permitindo que os pesquisadores registrassem suas experiências e observassem determinadas situações, como comportamentos e decisões empreendedoras. Além disso, à medida que aprofundavam seu contato e o acesso aos informantes, eles foram sendo considerados pelas comunidades como importantes "consultores". Ademais, essa aproximação trouxe uma visão mais crítica acerca das teorias existentes no campo de estudo.

As entrevistas documentadas totalizaram 123 horas de depoimentos, com 90 empresários brasileiros estabelecidos no exterior. O viés pessoal foi mínimo, porque dois dos pesquisadores realizaram a maioria das entrevistas face a face.

\subsection{ANÁLISE DOS DADOS}

O procedimento de análise seguiu uma abordagem qualitativa (O’Donnell \& Cummins, 1999; Denzin \& Lincoln, 2011), valendo-se do uso do software Atlas.ti e de um protocolo de análise, em diversas etapas.

Após a realização de múltiplos métodos para a coleta de dados, com predominância das entrevistas em profundidade, conforme relatado na seção anterior, foram extraídas várias citações, como exemplos de percepções e de comportamentos típicos dos empreendedores (Etapa 1). Na Etapa 2, foram identificados dois macrotemas, que emergiram das citações: "percepções de comunidades étnicas" e "orientação empresarial". Na Etapa 3, esses dois macrotemas foram divididos em duas subcategorias, da seguinte maneira: "percepções das comunidades étnicas" foi dividido em percepções "positivas" e "negativas" dos participantes em relação às suas comunidades étnicas; e em "orientação para os negócios", foram identificados os fatores que os levaram a favorecer 
Orientação de Mercado para Pequenas e Médias Empresas de Imigrantes Brasileiros no Exterior

seus "co-étnicos" ou "locais" como principal público. Esse protocolo de análise ajudou a organizar uma proposição de quatro escolhas estratégicas diferentes para o empreendedor, que estão discriminadas a seguir (Figura 4).

\section{DISCUSSÃO SOBRE A ORIENTAÇÃO DO MERCADO}

Zhou (2004) abordou diferentes categorias que refletiam as estruturas de oportunidade para empreendedores imigrantes, com base em três focos de mercado: (1) nichos de mercado étnicos, que atendem aos gostos específicos (comida, vestuário etc.) da comunidade étnica; (2) oportunidades no mercado convencional, preenchendo, por exemplo, demandas não atendidas por empreendedores locais, em bairros pobres, como farmácias, mercearias ou lojas de conveniência; e (3) venda de produtos exóticos para os clientes locais. Apesar de citar essas orientações de mercado, a autora não dá destaque à categorização, por se tratar de um texto sociológico, que se debruça sobre a análise da comunidade de Chinatown, em Nova York.

No entanto, as evidências empíricas, levantadas pelos autores deste artigo, apontaram uma quarta categoria, não mencionada por Zhou (2004), que envolve a separação das oportunidades, no mercado convencional, em duas: (1) interesses específicos e negócios de minorias intermediárias; e (2) mercado genérico local.

Para chegar a essa matriz, com quatro categorias, os autores recorreram, além das evidências de campo, aos textos seminais e revisitados sobre "estratégia e orientação de mercado", tais como Ansoff (1957), Stonehouse e Snowdon (2007), Hinterhuber (2013) e Novo e Padilha (2017).

O output final dessa nova abordagem confere um enfoque mais gerencial à proposta de Zhou (2004), além de categorizar, por uma matriz $2 \times 2$, os possíveis eixos que orientam as escolhas mercadológicas de empreendedores imigrantes ou étnicos: (a) a afiliação com o enclave étnico, fruto de seu capital social de e redes de relacionamento; e (b) o mercado-alvo escolhido. As evidências de campo, a seguir, foram coletadas em comunidades imigrantes brasileiras, estabelecidas no exterior, conforme descrito na seção sobre a metodologia de pesquisa. (Figura 3) 


\begin{tabular}{|c|c|c|c|}
\hline \multicolumn{4}{|c|}{ Desenvolvimento de categorias } \\
\hline $\begin{array}{l}\text { Categorias de } \\
\text { organização } \\
\text { preliminar }\end{array}$ & Citações dos respondentes & $\begin{array}{l}\text { Sentimentos } \\
\text { e percepções }\end{array}$ & $\begin{array}{l}\text { Categorias } \\
\text { finais }\end{array}$ \\
\hline \multirow{3}{*}{$\begin{array}{l}\text { Percepções de } \\
\text { comunidades } \\
\text { étnicas }\end{array}$} & Faço comida em casa e vendo de porta em porta. $\cdot$ As igrejas nos dão suporte. & Apoio & \multirow{2}{*}{$\begin{array}{c}\text { Têm afiliação } \\
\text { (Schimmele \& Wu, } \\
\text { 2015) }\end{array}$} \\
\hline & Falam a minha língua. $•$ Fazemos festa nos fins de semana. & Inclusão & \\
\hline & Não vim pra cá para viver com compatriotas, para isso ficava no meu país. & Repulsa & $\begin{array}{c}\text { Não têm afiliação } \\
\text { (Schimmele \& Wu, } \\
\text { 2015; Cruz, Falcão, \& } \\
\text { Barreto, 2017) }\end{array}$ \\
\hline \multirow{8}{*}{$\begin{array}{l}\text { Preocupações } \\
\text { de orientação } \\
\text { de negócios }\end{array}$} & $\begin{array}{l}\text { O mercado local é muito mais competitivo. } \cdot \text { Entendo tudo de carne, por isso, abri uma } \\
\text { churrascaria. } \cdot \text { Trabalhei com revenda de carro e aprendi os macetes. } \cdot \text { Sou jornalista, } \\
\text { quando cheguei aqui percebi que podia editar um jornal sem precisar validar meu diploma. }\end{array}$ & Conhecimento & \multirow{3}{*}{$\begin{array}{c}\text { Foco no mercado } \\
\text { étnico } \\
\text { (Achidi-Ndofor \& } \\
\text { Priem, 2011) }\end{array}$} \\
\hline & $\begin{array}{l}\text { Os compatriotas sentem falta de empresas étnicas. } • \text { As pessoas sentem falta do produto } \\
\text { "de casa". }\end{array}$ & Vontade de empreender & \\
\hline & Fiquei desesperado até achar um restaurante com comida do meu país. & Saudade & \\
\hline & Não gosto de trabalhar para os compatriotas, pois eles não querem pagar o preço justo. & Repulsa & \multirow{3}{*}{$\begin{array}{c}\text { Foco no mercado } \\
\text { local } \\
\text { (Altinay, 2009) }\end{array}$} \\
\hline & O mercado local é muito maior e rende mais lucro. & Oportunidade & \\
\hline & Minha experiência de trabalho local foi fundamental para abrir meu negócio. & Conhecimento & \\
\hline & Eles precisavam de alguém que prestasse o serviço, falando a língua deles. & Oportunidade & \multirow{2}{*}{$\begin{array}{l}\text { Aceita as duas } \\
\text { possibilidades. }\end{array}$} \\
\hline & Não achava fornecedores para repetir o negócio, que fazia no meu país. & Dificuldade de empreender & \\
\hline
\end{tabular}

Figura 3. Categorias emergentes das evidências de campo

Fonte: Elaborada pelo autor. 
Ao organizar as evidências de campo, pode-se perceber dois componentes, presentes nos discursos dos empresários imigrantes brasileiros no exterior: (1) sua relação com o enclave; e (2) sua percepção mercadológica. Dessa forma, esses componentes tornam-se os dois eixos principais da matriz proposta.

Especificamente no que se refere à relação com as comunidades étnicas ou enclaves étnicos, os autores notaram a existência de dois grupos de sentimentos confrontantes: (1) positivos, como segurança, apoio e inclusão; e (2) negativos, como repulsa, desconfiança e desamparo. O fenômeno da desconfiança e do afastamento (mistrust), identificado em algumas comunidades brasileiras (Cruz, Falcão, \& Barreto, 2017), não havia sido descrito na literatura prévia sobre empreendedorismo de imigrantes. Não se pode afirmar, ainda, que se trata de um fenômeno exclusivamente associado aos brasileiros; porém, os autores deste artigo, corroboram o trabalho prévio de Cruz, Falcão e Barreto (2017), pois acreditam que, na medida em que a literatura sobre o tema avançar, outros relatos poderão conferir robustez ao assunto.

No que tange à orientação dos negócios imigrantes, as evidências de campo apontam claramente um grupo de empresários que enfocam no próprio enclave (étnicos e co-étnicos); e outros que buscam o mercado local (o cidadão nacional do país de acolhimento). A Figura 4, portanto, resulta dessa tentativa de sistematizar os achados da pesquisa, incluindo os dois eixos identificados.

\begin{tabular}{|c|c|c|c|}
\hline & & \multicolumn{2}{|c|}{ Afiliação com a comunidade étnica } \\
\hline & & Sim & Não \\
\hline \multirow{2}{*}{  } & Étnicos e co-étnicos & Mercado de nicho étnico. & $\begin{array}{l}\text { Interesses específicos e } \\
\text { negócios de minorias } \\
\text { intermediárias. }\end{array}$ \\
\hline & Consumidor local & $\begin{array}{l}\text { Mercado de produtos exóticos } \\
\text { para o cliente local. }\end{array}$ & Mercado genérico local. \\
\hline
\end{tabular}

Figura 4. Oportunidades de mercado para empreendedores imigrantes Fonte: Elaborada pelo autor.

A seguir, são descritas e discutidas as quatro orientações mercadológicas derivadas da afiliação e das escolhas de mercados-alvo.

\subsection{MERCADO DE NICHO ÉTNICO}

As limitações da língua promovem barreiras de comunicação aos imigrantes estrangeiros, quando eles se inserirem em novos ambientes. Esse é um fator importante para a afiliação étnica entre os imigrantes (Schimmele \& Wu, 2015). Por outro lado, 
mercados protegidos, como os que estão no ambiente do enclave, podem promover barreiras linguísticas e culturais à concorrência. Além disso, as empresas étnicas se valem de seu conhecimento tradicional e de seu know-how sobre como atender seus compatriotas, sobretudo os clientes dos produtos étnicos (alimentos, vestuário, serviços étnicos e itens religiosos) (Altinay, 2009).

Uma de suas implicações está relacionada ao foco das empresas étnicas em se estabelecer no enclave, que oferece demandas étnicas específicas (Portes \& Zhou, 1992).

Segundo Achidi-Ndofor e Priem (2011), quando empreendedores imigrantes estão socialmente identificados com suas comunidades étnicas, eles se tornam mais propensos a fornecer produtos e serviços para consumidores do enclave, sendo ligados às suas comunidades por tradição, por prestígio ou por destino. As entrevistas em profundidade evidenciaram que essa escolha mercadológica é típica de empreendedores que experimentaram trajetórias irregulares de imigração. Alguns chegaram ao país de acolhimento com visto de turista ou de estudante (e decidiram ficar, após conseguirem se sustentar). Já outros, tentam a sorte, por meio de um ingresso ilegal, entrando sem permissão no país de acolhimento.

A escolha de mercado do nicho étnico, no entanto, não é exclusiva desse tipo de empreendedor imigrante. Empresários com trajetórias regulares (executivos expatriados, cidadãos com dupla cidadania ou migrantes com casamentos programados) poderiam optar por atender ao mercado étnico, por razões explicadas mais adiante. Essa oportunidade se torna efetiva, devido à afiliação a um ambiente menos competitivo, devido ao número de empresas que competem no enclave - que, em geral, é muito menor do que a alta concorrência, no mercado principal. Os tipos de organizações que fazem parte desse grupo estão descritos a seguir.

(A) Empresas sem um produto ou serviço com apelo étnico, mas que utilizam sua origem nacional para se tornar referência de atendimento à comunidade imigrante, usando a vantagem de um "toque especial" ou do "jeitinho brasileiro". O importante é aproveitar uma identidade cultural, que alavanca o relacionamento e o networking, para atender aos clientes, de acordo com suas expectativas "étnicas" (Cruz, Falcão, \& Barreto, 2018). Exemplos: empresas de fornecimento e serviços gerais, como instalações de ar condicionado, concessionárias de automóveis, gráficas, escritórios de contabilidade, óticas, empresas de turismo etc.

(B) Empresas que usam o apelo étnico para oferecer bens e serviços ao exterior, da mesma forma que em sua terra natal, porém, às vezes, com certas adaptações aos insumos locais, como temperos ou alguns ingredientes (menos ou mais picantes, 
substituindo tapioca por farinha de trigo etc.); às regulamentações locais; e aos requisitos de logística de importação, em relação aos ingredientes típicos de receitas tradicionais (Teixeira, 2001; Teixeira, 2014; Teixeira \& Souza, 2014). Exemplos: churrascarias, franquias brasileiras de fast-food e padarias especializadas.

(C) Empresas de mídia étnica: jornais e revistas locais (impressos ou digitais), voltados ao nicho de mercado étnico. Essas publicações foram encontradas em todas as comunidades brasileiras no exterior, embora também sejam comuns a outros grupos. Nesse caso, devido aos custos operacionais e ao tipo de anunciante, pode ser mais sustentável, quando desenvolvido em comunidades étnicas maiores, com um número de potenciais anunciantes.

\subsection{INTERESSES ESPECÍFICOS OU NEGÓCIOS DE MINORIAS INTERMEDIÁRIAS}

Apesar do tamanho das oportunidades envolvidas em certos mercados étnicos (como, Chinatown, por exemplo), alguns empreendedores evitam a convivência ou o relacionamento comercial com seus grupos étnicos. Muitas vezes, eles tentam dissociarse deles, como sugerido por Ellemers, Van Rijswijk, Roefs e Simons (1997) ou Spears, Doosje e Ellemers (1997). Esses empreendedores vislumbram uma oportunidade de mercado diferente (e mais competitiva), enquanto usam suas vantagens competitivas étnicas (Novo \& Padilha, 2017) para atender ao público local.

Os artigos seminais sobre as minorias intermediárias (Bonacich, 1973) inspiraram essa categoria, composta por empreendedores que buscam lucrar com mercados étnicos, embora sem envolvimento da comunidade.

A diáspora judaica, na Europa Oriental e nos países do Mediterrâneo, é um dos melhores exemplos das redes transnacionais de comércio das minorias intermediárias (Safran, 1991, 2005). Outro exemplo típico é a diáspora chinesa, no sul da Ásia (Gerke \& Menkhoff, 2003), ou a indiana, na África Oriental (Adam, 2015), com predominância em determinados setores da economia. Mais recentemente, os chineses também desenvolveram o mesmo tipo de rede de comércio entre as "Chinatowns" dos países ocidentais e importantes centros comerciais asiáticos, como Hong Kong, Guanzhou e Taiwan (Elo \& Volovelsky, 2016).

As atividades típicas das minorias intermediárias, segundo Bonacich (1973), são: agentes de negócios, empreiteiros, coletores de aluguel, agiotas e comerciantes em geral, que servem como intermediários entre produtores e consumidores. Zhou (2004) reforça 
as definições apresentadas por Bonacich (1973), observando que elas preenchem uma lacuna de status entre as elites das sociedades locais e as massas de consumidores.

Interesses específicos dizem respeito a certas atividades, que poderiam ser lucrativas, como turismo, construção civil, comércio etc. Por exemplo, devido ao surgimento de destinos turísticos populares, em todo o mundo, alguns empresários étnicos decidem abrir pequenas casas de hóspedes, restaurantes ou lojas étnicas. No caso brasileiro, a cidade de Orlando é um exemplo típico, onde, conforme relatado por Liston (2014), essa escolha de mercado se dá devido à concentração de turistas brasileiros. Nessa localidade, os donos de lojas promovem o seu comércio, independentemente da sua relação com o enclave étnico local. Uma característica particular, de todos esses empresários, é o uso da língua portuguesa como justificativa para aplicar margens superiores a produtos específicos, que simbolizam o consumo de moda dos brasileiros até hoje. Vale à pena notar que a maioria é de brasileiros, mas há também lojistas de diferentes origens latino-americanas, que se aproveitam da familiaridade com a língua portuguesa. É curioso que os empresários norte-americanos não se aventuram nesse nicho específico de mercado, provavelmente devido às barreiras linguísticas.

Deve-se enfatizar que, nesse caso, o foco não está na comunidade de imigrantes, mas no consumidor turístico, seja da mesma origem que o empreendedor, seja similar (latino). Exemplos do caso brasileiro são empresas que vendem suplementos alimentares, eletrônicos e celulares.

A cidade de Orlando é um destino top-of-mind, no que diz respeito a esse tipo de negócio turístico, de acordo com a Associação Brasileira de Agências de Viagens (ABAV, 2019). Hoje, graças a blogs, mídias sociais e sites de turismo, é possível identificar essas lojas com a estratégia étnica, ao planejar suas viagens.

Outra vantagem estratégica, apresentada por essas empresas, diz respeito à disponibilidade de determinados produtos. Por estar constantemente em contato com seus consumidores-alvo, eles podem prever uma alta demanda para certos produtos (por exemplo, certa bolsa de Michael Kors, que foi mostrada em uma novela brasileira, ou o recém-lançado iPhone). Uma das lojas-alvo brasileiras, por exemplo, adquiriu um contêiner completo de aparelhos iPhone, enquanto, nas lojas oficiais, eles estavam esgotados e, possivelmente, indisponíveis. Na verdade, esses empresários decidiram cobrar $35 \%$ a mais do que a loja regular da Apple, conforme relatado por um empresário entrevistado. Segundo um dos clientes dessa loja: "para mim vale a pena, porque... no Brasil, ainda custaria mais do que o dobro". 


\subsection{MERCADO DE PRODUTOS EXÓTICOS PARA O CONSUMIDOR LOCAL}

As redes étnicas fornecem "estoques de mão de obra", fornecedores, conhecimentos e clientes (Barrett, Jones, \& McEvoy, 1996). No entanto, alguns empresários usam conhecimentos tradicionais e conexões para melhorar seus lucros, enquanto vendem para o mercado local, o que é chamado por Altinay (2009) de "clientes tradicionais". Esse foco de mercado está relacionado à estratégia de desenvolvimento de mercado, proposta pelo trabalho seminal de Ansoff (1957).

Esse tipo de empreendedor pode aproveitar a tendência da moda globalizada de produtos étnicos (por exemplo, sushi bars, churrascarias argentinas e brasileiras, tacos mexicanos ou chocolates belgas e suíços). Alguns até tentam desenvolver uma cultura de consumo, em certas áreas do mundo, onde não há imigração ou moda estabelecida.

No caso brasileiro, os exemplos são as churrascarias-rodízio, o açaí, o treinamento de artes marciais (jiu-jitsu), os serviços de depilação e manicure, e os vários tipos de biquini sexy, todos tipicamente tupiniquins (Teixeira, 2014; Rocha, Esteves, Mello, \& Silva, 2015). Além disso, a oportunidade empreendedora recebe um fator de facilitação: uma demanda criada pelo próprio desejo de conhecer ou de experimentar essa novidade.

Ademais, alguns imigrantes tentam persuadir os clientes tradicionais a incorporar esses produtos ou serviços em suas vidas diárias (Wang \& Altinay, 2012). No caso das comunidades brasileiras, destacam-se alguns produtos e serviços, como o ensino de capoeira, ou de produtos menos conhecidos, como pastéis fritos e pães de queijo.

Essa oportunidade de mercado, de vender produtos exóticos brasileiros, é similarmente utilizada por pequenos grupos de imigrantes ou refugiados, que chegam ao Brasil. Pode-se citar como exemplo, a culinária árabe e a história do refugiado sírio TalalAl Tinawi, que vive em São Paulo. No aniversário da filha, o ex-engenheiro, que chegou ao Brasil em 2013, e fez fortuna vendendo seus quitutes (Azevedo, 2015), decidiu dar uma festa, servindo pratos típicos. Com isso, ele encantou os novos amigos brasileiros, que passaram a pedir mais dessas "iguarias". Um amigo fez a sua fanpage no Facebook, para divulgação, e depois disso, ele participou de feiras, na mesquita local, no Museu da Imigração e em eventos de várias organizações de refugiados, na cidade. Um voluntário, de uma organização de ajuda aos refugiados, sugeriu um site brasileiro, de financiamento coletivo, como meio de ele levantar capital para abrir seu próprio restaurante ou caminhão de alimentos. Graças a essa ajuda e às ferramentas digitais, no ano de 2016, seu restaurante foi inaugurado (Brandino, 2016). Embora haja uma comunidade árabe estabelecida em São Paulo, e os moradores locais já conheçam alimentos sírio-libaneses, 
ao apresentar a receita original da sua terra, o cliente a receberá, apreciando também o "caso de sucesso de refugiado" que ela naturalmente simboliza.

O mesmo glamour pode ser evidenciado nos lutadores de jiu-jitsu, que se tornaram celebridades nos EUA, após ganharem campeonatos de Ultimate Fighting, alavancando vertiginosamente o negócio das academias de Brazilian Jiu-Jitsu, em terras norteamericanas (Rocha, Esteves, Mello, \& Silva, 2015).

\subsection{MERCADO GENÉRICO LOCAL}

Dois fatores influenciam a orientação para atender ao mercado genérico local, que é altamente competitivo: (1) a existência de uma comunidade de consumidores étnicos significativa (ou lucrativa); e (2) a assimilação "completa" de imigrantes por sua comunidade local (Alba \& Nee, 1997). Esse tipo de empresa poderia ser enquadrado como "apenas uma outra empresa" no mercado, indicando que a literatura de empreendedorismo imigrante dificilmente aborda esse fenômeno.

No entanto, de acordo com Cruz, Falcão e Barreto (2017), certa "desconfiança limitada" foi uma novidade encontrada nas comunidades brasileiras de empreendedores. Além disso, a orientação dos brasileiros para o mercado é caracterizada pelas relações comerciais pré-estabelecidas com fornecedores e clientes locais, e pela falta de afiliação cultural.

Nesse contexto, de acordo com Novo e Padilha (2017), o empreendedor estará sujeito às forças, sem o benefício de diminuir a competição. Embora as perspectivas de mercado sejam muito mais amplas nesse caso, os empresários provavelmente enfrentarão uma concorrência acirrada. Esse é o caso de alguns empreendedores imigrantes, por exemplo, que decidem abrir escritórios de seguros, empresas de tecnologia, restaurantes, serviços de lavagem a seco, ou qualquer outro tipo de negócio sem apelo étnico, ou seja, não direcionados a nenhum grupo em particular, como os mencionados anteriormente nesta seção.

\section{CONSIDERAÇÕES FINAIS}

O mundo enfrenta um desafio complexo no que tange ao crescimento da imigração, que inclui fluxos de mentes, ideias, bens e indivíduos - sendo alguns, oriundos das minorias empreendedoras imigrantes.

Diante da lacuna teórica, observada na interseção entre os estudos dos empreendedorismos de diáspora e étnico, esta pesquisa, que teve a finalidade de alimentar a discussão sobre o assunto, evidenciou, por meio da sistematização do conhecimento, sob uma abordagem gerencial, variáveis passíveis de influenciar a 
definição de estratégias de mercado das empresas étnicas ou constituídas por imigrantes. Ademais, este estudo logrou responder às perguntas relativas à influência da afiliação étnica e suas implicações na escolha de diferentes estratégias e orientações mercadológicas, assim como a questão acerca da definição do público-alvo das empresas (étnicos, co-étnicos, consumidores ou clientes locais).

Diante do exposto na seção anterior, a pesquisa contribui para a análise e a compreensão das atividades empreendedoras de imigrantes ou cidadãos da diáspora, em seus países de acolhimento, visto que confronta uma robusta coleta de dados com uma revisão abrangente da literatura sobre o tema. O empreendedorismo imigrante, em seu sentido mais amplo, surge como uma forma de conectar e de desenvolver pessoas, grupos culturais e mercados. Além disso, as empresas imigrantes têm efeitos favoráveis na ressocialização dos indivíduos, gerando tanto renda quanto benefícios não econômicos.

Partindo de dois pontos levantados por Min e Bozorgmehr (2000) - se os recursos étnicos são mais importantes para o estabelecimento de empresas imigrantes ou étnicas; e se existe uma conexão causal entre negócios étnicos e solidariedade étnica - concluise que é possível discutir especificidades dentro da mesma etnia. Por exemplo, os brasileiros com baixo nível educacional (capital humano) ou poucas conexões locais (capital social), tendem a confiar mais em recursos étnicos para trabalhar em seus negócios, escolhendo esse público para atender. Em contrapartida, os brasileiros que possuem um capital humano e social mais elevado, ou mesmo os que foram expatriados, podem evidenciar padrões semelhantes aos dos imigrantes iranianos, desenvolvendo negócios maiores, mais dispersos e focados no atendimento dos consumidores locais.

Ainda corroborando os achados de Min e Bozorgmehr (2000), os brasileiros, que atendem à sua etnia, enfrentaram uma dura competição dentro do seu grupo étnico; enquanto os que optaram por atender aos clientes não-étnicos, como os iranianos, contornaram-na. Por isso, conclui-se que as empresas intermediárias, que vendem produtos exóticos para consumidores locais, ou visem a interesses específicos, são as que fortalecem sua solidariedade étnica. No entanto, mesmo sabendo que todos os tipos de empreendimentos imigrantes ou étnicos podem contribuir para a afiliação étnica, alguns estão mais apegados a seus grupos do que outros. Uma das principais contribuições teóricas deste artigo é apoiar, por intermédio da introdução de elementos associados às decisões estratégicas, a discussão sobre a orientação para o mercado de pequenos e médios negócios imigrantes e de empreendimentos étnicos de brasileiros no exterior, e acerca da escolha do tipo de público-alvo a ser atendido. 
Isso corrobora o que Elo et al. (2018) ressaltam, a respeito das inúmeras implicações relacionadas à base de recursos, dos desafios na natureza complexa e multidisciplinar do empreendedorismo imigrante, e da necessidade de uma análise em várias camadas. Assim, este estudo também considera que a mudança de estruturas rígidas para um entendimento mais amplo e profundo aumenta a riqueza do conjunto de conhecimentos relativos ao empreendedorismo de imigrantes, contribuindo com a teoria e a prática. Contudo, há ainda espaço para melhorias quanto às definições e ao tratamento conceitual aqui apresentados, sobretudo quando se trata da comparação entre diferentes contextos.

Mesmo que embasada em literatura referente a outras etnias, e tendo apresentado insights para apoiar futuros estudos comparativos sobre os empreendedorismos imigrante e étnico, conduzidos no seio de outras comunidades, esta pesquisa limitou-se a analisar um grupo étnico específico (brasileiros), com uma coleta de dados pautada em uma abordagem qualitativa. Sugere-se, pois, a realização de novos estudos, guiados por análises quantitativas, a fim de validar estatisticamente e de generalizar para outros contextos, os achados aqui apresentados. Como os cidadãos brasileiros são também descendentes de várias origens étnicas (asiática, árabe, europeia, africana e indígena), e o Brasil é, ao mesmo tempo, um país emissor e anfitrião imigrante, composto por um caldeirão de raças, ele se configura como um campo de observação que permite um olhar mais eclético do fenômeno estudado. Isso aponta caminhos para pesquisas comparativas, com outras comunidades imigrantes, o que pode fornecer, inclusive, novas dimensões relativas aos processos de orientação de mercado e às decisões estratégicas de pequenas empresas imigrantes e étnicas, vinculando-as às teorias do IE.

As implicações relativas à formulação de políticas abrangem a contribuição deste estudo para áreas que vão além do empreendedorismo. Políticas de migração e de integração, bem como o desenvolvimento social e oportunidades de mercado (Brinkerhoff, 2016) podem se beneficiar dos resultados apresentados, seguindo o exemplo de Newland e Tanaka (2010). Notavelmente, a afiliação e o público-alvo das empresas podem também contribuir para aprimorar aspectos institucionais formais e fomentar outros modos de integração social (Etemad, 2018).

No tocante às implicações práticas, este trabalho apresenta uma diretriz para futuros empreendedores imigrantes, que enfrentam dilemas relacionados tanto à sua orientação de mercado quanto ao direcionamento de suas decisões de negócio. Além disso, ele pode auxiliar os empreendedores com reflexões teóricas sobre as suas atividades.

Nesse sentido, um debate acadêmico mais amplo sobre o assunto, envolvendo a análise de diferentes grupos de imigrantes, ainda não observados pela literatura 
acadêmica, será bem-vindo. Um viés particularmente interessante, para estudos posteriores, inclui o uso da matriz ora apresentada, em estudos longitudinais, capturando a possível evolução (ou mudança de status) entre seus quadrantes. Outros possíveis caminhos de pesquisa incluem a incorporação dos "liabilities of outsidership and foreigness" do Modelo de Upsalla (Johanson \& Vahlne, 2009) na análise matricial.

\section{REFERÊNCIAS}

Achidi-Ndofor, H., \& Priem, R. L. (2011). Immigrant entrepreneurs, the ethnic enclave strategy, and venture performance. Journal of Management, 37(3), 790-818.

Adam, M. (Ed.). (2015). Indian Africa: Minorities of Indian-Pakistani Origin in Eastern Africa. Tanzania: Mkuki Na Nyota Publishers.

Agarwal, S., Erramilli, M.K., \& Dev, C. (2003). Market orientation and performance in service firms: role of innovation. Journal of Services Marketing, 17(1), 68-82.

Alba, R., \& Nee, V. (1997). Rethinking assimilation theory for a new era of immigration. International migration review, 31(4), 826-874.

Aldrich, H. E., \& Waldinger, R. (1990). Ethnicity and entrepreneurship. Annual review of sociology, 16(1), 111-135.

Aliaga-Isla, R., \& Rialp, A. (2013). Systematic review of immigrant entrepreneurship literature: previous findings and ways forward. Entrepreneurship \& Regional Development, 25(9-10), 819-844.

Altinay, L. (2009). Market orientation of small ethnic minority-owned hospitality firms. International Journal of Hospitality Management, 29(1), 148-156.

Altinay, L., \& Altinay, E. (2006). Determinants of ethnic minority entrepreneurial growth in the catering sector. The Service Industries Journal, 26(2), 203-221.

Altinay, L., \& Altinay, E. (2008). Factors influencing business growth: the rise of Turkish entrepreneurship in the UK. International Journal of Entrepreneurial Behavior \& Research, 14(1), 24-46.

Ansoff, H. I. (1957). Strategies for diversification. Harvard business review, 35(5), 113-124.

ABAV - Associação Brasileira de Agências de Viagens. (2019). Férias de julho: confira os destinos mais procurados por brasileiros em 2019. Press Releases. Recuperado de http://www.abav.com.br/pa/press-release/ferias-de-julho-confira-os-destinos-mais-

procurados--por-brasileiros-em-2019

Azevedo, R. (2015). Só volto à Síria para visitar, diz refugiado no Brasil. Revista Exame. Recuperado de http://exame.abril.com.br/brasil/so-volto-a-siria-para-visitar-diz-refugiado-nobrasil/

Barrett, G. A., Jones, T. P., \& McEvoy, D. (1996). Ethnic minority business: Theoretical discourse in Britain and North America. Urban studies, 33(4-5), 783-809. 
Blackburn, R., \& Kovalainen, A. (2009). Researching small firms and entrepreneurship: Past, present and future. International Journal of Management Reviews, 11(2), 127-148.

Bloem, T. M. (2015). Impacts of Brazilian Business and Brazilian Immigrant Organizations in South Florida (Master Dissertation). Faculty of the Center for Latin American Studies, University of Arizona, Arizona, USA.

Bonacich, E. (1973). A theory of middleman minorities. American sociological review, 38(5), 583-594.

Brandino, G. (2016). Família síria inaugura restaurante e divide alegria com voluntários e fregueses. Migra Mundo. Recuperado de http://migramundo.com/familia-siria-inaugurarestaurante-e-divide-alegria-com-voluntarios-e-fregueses/

Brinkerhoff, J. M. (2016) Institutional Reform and Diaspora Entrepreneurs: The In-Between Advantage. Oxford: Oxford University Press.

Cheong, P. H., Edwards, R., Goulbourne, H., \& Solomos, J. (2007). Immigration, social cohesion and social capital: A critical review. Critical social policy, 27(1), 24-49.

Cohen R (2008). Global diasporas: an introduction (2nd ed.). New York: Routledge.

Coviello, N., \& Yli-Renko, H. (Eds.). (2016). Handbook of Measures for International Entrepreneurship Research: Multi-item Scales Crossing Disciplines and Contexts. Cheltenham, UK: Edward Elgar Publishing.

Cruz, E. P., Falcão, R. P. Q., \& Barreto, C. R. (2017). Bounded Trust or Mistrust-Depicting Brazilian Immigrant Entrepreneurship Practices in the US. Poster presented at the United States Association for Small Business and Entrepreneurship (USASBE). Annual Conference, Philadelphia, Unites States of America, 32.

Cruz, E. P., Falcão, R. P. Q., \& Barreto, C. R. (2018). Exploring the evolution of ethnic entrepreneurship: the case of Brazilian immigrants in Florida. International Journal of Entrepreneurial Behavior \& Research, 24(5), 971-993.

Deng, S., \& Dart, J. (1994). Measuring market orientation: a multi-factor, multi-item approach. Journal of marketing management, 10(8), 725-742.

Denzin, N. K., \& Lincoln, Y. S. (Eds.). (2011). The Sage handbook of qualitative research. Thousand Oaks, CA: Sage.

Dimitratos, P., Plakoyiannaki, E., Pitsoulaki, A., \& Tüselmann, H. J. (2010). The global smaller firm in international entrepreneurship. International Business Review, 19(6), 589-606.

Drori, I., Honig, B., \& Wright, M. (2009). Transnational entrepreneurship: An emergent field of study. Entrepreneurship Theory and Practice, 33(5), 1001-1022.

Dubois, A., \& Gadde, L. E. (2002). Systematic combining: an abductive approach to case research. Journal of business research, 55(7), 553-560.

Ellemers, N., Van Rijswijk, W., Roefs, M., \& Simons, C. (1997). Bias in intergroup perceptions: balancing group identity with social reality. Personality and Social Psychology Bulletin, 23(2), 186-198. 
Elo, M. (2016). Typology of diaspora entrepreneurship: case studies in Uzbekistan. Journal of International Entrepreneurship, 14(1), 121-155.

Elo, M., \& Volovelsky, E. K. (2016). Jewish diaspora entrepreneurs - the impact of religion on opportunity exploration and exploitation. International Journal of Entrepreneurship and Small Business, 31(2), 244-269.

Elo, M., Sandberg, S., Servais, P., Basco, R., Cruz, A. D., Riddle, L., \& Täube, F. (2018). Advancing the views on migrant and diaspora entrepreneurs in international entrepreneurship. Journal of International Entrepreneurship, 16(2), 119-133.

Etemad, H. (2017). Towards a conceptual multilayered framework of international entrepreneurship. Journal of International Entrepreneurship, 15(3), 229-238.

Etemad, H. (2018). Advances and challenges in the evolving field of international entrepreneurship: The case of migrant and diaspora entrepreneurs. Journal of International Entrepreneurship, 16(2), 109-118.

Evans, Y., Wills, J., Datta, K., Herbert, J., Mcllwaine, C., May, J., ... \& França, A. P. (2007). Brazilians in London: a report for the Strangers into Citizens Campaign. London: Department of Geography, Queen Mary, University of London.

Forsander, A. (2004). Social capital in the context of immigration and diversity: Economic participation in the Nordic welfare states. Journal of International Migration and Integration/Revue de l'integration et de la migration internationale, 5(2), 207-227.

Gerke, S., \& Menkhoff, T. (Eds.). (2003). Chinese entrepreneurship and Asian business networks. New York: Routledge.

Herreros, F., \& Criado, H. (2009). Social trust, social capital and perceptions of immigration. Political studies, 57(2), 337-355.

Hinterhuber, A. (2013). Can competitive advantage be predicted? Management Decision, 51(4), 795-812.

Hurtado-de-Mendoza, A., Gonzales, F. A., Serrano, A., \& Kaltman, S. (2014). Social isolation and perceived barriers to establishing social networks among Latina immigrants. American journal of community psychology, 53(1-2), 73-82.

Jamal, A. (2003). Retailing in a multicultural world: the interplay of retailing, ethnic identity and consumption. Journal of Retailing and Consumer Services, 10(1), 1-11.

Jaworski, B. J., \& Kohli, A. K. (1993). Market orientation: antecedents and consequences. Journal of marketing, 57(3), 53-70.

Johanson, J., \& Vahlne, J. E. (2009). The Uppsala internationalization process model revisited: From liability of foreignness to liability of outsidership. Journal of international business studies, 40(9), 1411-1431.

Jones, T., \& Ram, M. (2010). Ethnic variations on the small firm labour process. International Small Business Journal, 28(2), 163-173. 
Jones, T., Barrett, G., \& McEvoy, D. (2000). Market potential as a decisive influence on the performance of ethnic minority business. In Immigrant Businesses (pp. 37-53). UK: Palgrave Macmillan.

Kara, A., Spillan, J. E., \& DeShields Jr., O. W. (2005). The effect of a market orientation on business performance: a study of small-sized service retailers using Markor scale. Journal of small business management, 43(2), 105-118.

Kirca, A. H., Jayachandran, S., \& Bearden, W. O. (2005). Market orientation: A meta-analytic review and assessment of its antecedents and impact on performance. Journal of marketing, 69(2), 24-41.

Kozinets, R. V. (2002). The field behind the screen: Using netnography for marketing research in online communities. Journal of marketing research, 39(1), 61-72.

Lee, J. (1999). Retail niche domination among African American, Jewish, and Korean entrepreneurs: competition, coethnic advantage and disadvantage. American Behavioral Scientist, 42(9), 1398-1416.

Light, I., Bhachu, P., \& Karageorgis, S. (1993). Migration networks and immigrant entrepreneurship. In I. Light \& P. Bhachu (Eds.). Immigration and entrepreneurship: Culture, capital, and ethnic networks (pp. 25-50). London/New York: Routledge.

Liston, B. (2014). Turistas brasileiros superam britânicos e lideram visitas à Flórida. Reuters Brasil.

http://br.reuters.com/article/entertainmentNews/idBRKBN0F65GE20140701.

Luken, V. M., \& Tranmer, M. (2010). Personal support networks of immigrants to Spain: A multilevel analysis. Social Networks, 32(4), 253-262.

Marschan-Piekkari, R., \& Welch, C. (Eds.). (2011). Rethinking the case study in international business and management research. Cheltenham, UK: Edward Elgar Publishing.

Matsuno, K., Mentzer, J. T., \& Rentz, J. O. (2005). A conceptual and empirical comparison of three market orientation scales. Journal of business research, 58(1), 1-8.

McCartan-Quinn, D., \& Carson, D. (2003). Marketing orientation in SMEs: Ef-fects on the internal environment. New England Journal of Entrepreneurship, 5(1), 13-22.

McCracken, G. (1988). The Long Interview. Beverly Hills, CA: Sage.

Min, P. G., \& Bozorgmehr, M. (2000). Immigrant entrepreneurship and business patterns: A comparison of Koreans and Iranians in Los Angeles. International migration review, 34(3), 707-738.

Moussetis, R. (2011). Ansoff revisited: How Ansoff interfaces with both the planning and learning schools of thought in strategy. Journal of Management History, 17(1), 102-125.

Newland, K., \& Tanaka, H. (2010). Mobilizing diaspora entrepreneurship for development. Washington, DC: Migration Policy Institute.

Nkongolo-Bakenda, J. M., \& Chrysostome, E. V. (2013). Engaging diasporas as international entrepreneurs in developing countries: in search of determinants. Journal of International Entrepreneurship, 11(1), 30-64. 
Novo, B., \& Padilha, F. (2017). Cinco forças de Porter: a prática nas empresas. Seminário de Gestão e Tecnologia, 1(1), 10-18.

O'Donnell, A., \& Cummins, D. (1999). The use of qualitative methods to research networking in SMEs. Qualitative Market Research: An International Journal, 2(2), 82-91.

Pelham, A. M. (2000). Market orientation and other potential influences on performance in small and medium-sized manufacturing firms. Journal of small business management, 38(1), 48-67.

Portes, A., \& Zhou, M. (1992). Gaining the upper hand: Economic mobility among immigrant and domestic minorities. Ethnic and Racial Studies, 15(4), 491-522.

Rath, J., \& Kloosterman, R. (2000). Outsiders' business: A critical review of research on immigrant entrepreneurship. International Migration Review, 34(3), 657-681.

Riddle, L., \& Brinkerhoff, J. (2011). Diaspora entrepreneurs as institutional change agents: The case of Thamel.com. International Business Review, 20(6), 670-680.

Riddle, L., Hrivnak, G. A., \& Nielsen, T. M. (2010). Transnational diaspora entrepreneurship in emerging markets: Bridging institutional divides. Journal of International Management, 16(4), 398-411.

Rocha, A. D., Esteves, F., Mello, R. C. D., \& Silva, J. F. D. (2015). Diasporic and Transnational Internationalization: The Case of Brazilian Martial Arts. BAR-Brazilian Administration Review, 12(4), 403-420.

Rusinovic, K. (2008). Moving between markets? Immigrant entrepreneurs in different markets. International Journal of Entrepreneurial Behavior \& Research, 14(6), 440-454.

Safran, W. (1991). Diasporas in modern societies: Myths of homeland and return. Diaspora: A journal of transnational studies, 1(1), 83-99.

Safran, W. (2005). The Jewish diaspora in a comparative and theoretical perspective. Israel studies, 10(1), 36-60.

Sarasvathy, S. D. (2001). Causation and effectuation: Toward a theoretical shift from economic inevitability to entrepreneurial contingency. Academy of management Review, 26(2), 243-263.

Saxenian, A. (2007). The new argonauts: Regional advantage in a global economy. Cambridge, Massachusetts, EUA: Harvard University Press.

Schimmele, C., \& Wu, Z. (2015). The new immigration and ethnic identity. Discussion Paper Series Document de travail, 3(1), 1-40.

Slater, S. F., \& Narver, J. C. (1994). Does competitive environment moderate the market orientation-performance relationship? The Journal of Marketing, 58(1), 46-55.

Spears, R., Doosje, B., \& Ellemers, N. (1997). Self-stereotyping in the face of threats to group status and distinctiveness: the role of group identification. Personality and Social Psychology Bulletin, 23(5), 538-553.

Stake, R. E. (2013). Multiple case study analysis. New York: Guilford Press. 
Stonehouse, G., \& Snowdon, B. (2007). Competitive advantage revisited: Michael Porter on strategy and competitiveness. Journal of Management Inquiry, 16(3), 256-273.

Tata, J., \& Prasad, S. (2015). Immigrant family businesses: social capital, network benefits and business performance. International Journal of Entrepreneurial Behavior \& Research, 21(6), 842-866.

Teixeira, C. (2001). Construindo uma economia étnica em Toronto, Canadá. Scripta Nova: Revista Electrónica de Geografía y Ciências Sociales, 94(77). Recuperado de http://www.ub.edu/geocrit/sn-94-77.htm

Teixeira, E. K. (2014). Fogo de Chão Steak House: empreendedorismo étnico versus marketing de experiência. Update-Revista de Gestão de Negócios, 1(1), 137-153.

Teixeira, E. K., \& de Souza, Y. S. (2014). A internacionalização das churrascarias brasileiras: uma análise sobre o ambiente de experiência. Revista Competência, 4(1), 1-15.

Tolciu, A. (2011). Migrant entrepreneurs and social capital: a revised perspective. International. Journal of Entrepreneurial Behavior \& Research, 17(4), 409-427.

Tzokas, N., Carter, S., \& Kyriazopoulos, P. (2001). Marketing and entrepreneurial orientation in small firms. Enterprise and innovation management studies, 2(1), 19-33.

United Nations. [Department of Economic and Social Affairs. Population Division]. (2017). International Migration Report 2017: Highlights. New York: United Nations.

Vandor, P., \& Franke, N. (2016). Why Are Immigrants More Entrepreneurial? Harward Business Review. Recuperado de https://hbr.org/2016/10/why-are-immigrants-moreentrepreneurial

Wang, C. L., \& Altinay, L. (2012). Social embeddedness, entrepreneurial orientation and firm growth in ethnic minority small businesses in the UK. International Small Business Journal, 30(1), 3-23.

Zhou, M. (2004). The Role of the Enclave Economy in Immigrant Adaptation and Community Building: The case of New York's Chinatown. In J. S. Butler \& G. Kozmetsky (Orgs.) Immigrant and Minority Entrepreneurship. The Continuous Rebirth of American Communities. London: Prager.

Zolin, R., \& Schlosser, F. (2013). Characteristics of immigrant entrepreneurs and their involvement in international new ventures. Thunderbird International Business Review, 55(3), 271-284. 